\title{
Análisis del crecimiento de las comunidades judías ortodoxas en Chile
}

Analysis of the growth of the Orthodox Jewish communities in Chile

Katherine Bäuerle Ewert kathybauerle@yahoo.com Universidad de Chile

Chile

\section{Resumen}

Este artículo analiza el aumento de las comunidades ortodoxas entre los judíos de Chile. Dichas comunidades han crecido exponencialmente en la última década, debido en buena parte a la aparición de instituciones ortodoxas que promueven el estudio de la Torá entre los jóvenes, una creciente apetencia de espiritualidad y el declive de las instituciones tradicionales de la comunidad judía secular chilena. Este es un trabajo de investigación periodística que mediante entrevistas a rabinos ortodoxos y miembros de la comunidad ortodoxa santiaguina pretende reconstruir la historia de las comunidades ortodoxas judías en Chile, sobre la cual no existen antecedentes bibliográficos.

Palabras clave: Judíos - Ortodoxos - Comunidades - Chile

\begin{abstract}
This article analyzes the increased growth of orthodox communities among Chilean Jews. These communities have risen dramatically in the past decade, due to the emergence of several orthodox institutions that promote the study of the Torah among young people; a growing demand for spirituality and a certain decline of the traditional institutions of Chile's secular Jews. This article is based on interviews with orthodox rabbis and members of Santiago's orthodox community and aims to reconstruct the history of Chile's Jewish orthodox communities, of which there are no bibliographical records in existence.
\end{abstract}

Keywords: Jews - Orthodox - Communities - Chile 


\section{Introducción}

El objetivo del presente trabajo para optar al Diplomado en Cultura Judía es demostrar que el número y tamaño de las comunidades ortodoxas judías ha aumentado significativamente en los últimos 15 años en Chile.

Ante la ausencia de estudios demográficos que puedan corroborar esta premisa, se llevó adelante un trabajo de investigación periodística, recurriéndose a entrevistas y revisión bibliográfica.

Las entrevistas realizadas con rabinos ortodoxos y miembros de la comunidad ortodoxa santiaguina han sido fundamentales también para poder reconstruir la historia de las comunidades judías en Chile, sobre la cual no existen antecedentes bibliográficos.

El presente trabajo se ordena en tres partes centrales: la definición de lo que se entiende por ortodoxia judía y las características de las dos grandes corrientes modernas de ésta; el crecimiento de las comunidades ortodoxas judías en el mundo, con énfasis en las comunidades judías de América Latina; y una revisión de la historia de las comunidades judías en Chile y las razones que explicarían su reciente auge.

\section{Qué es la ortodoxia judía y cómo se vive en el siglo XXI}

Para comprender la creciente presencia de comunidades judías ortodoxas en Chile debemos partir por explicar lo que se entiende por ortodoxia judía. Definida por la Encyclopedia Britannica como “(...) la religión de aquellos judíos que adhiere de manera más estricta a las creencias y las prácticas tradicionales", la ortodoxia judía considera tanto a la Ley escrita, la Torá, como la Ley oral -codificada en la Mishná e interpretada en el Talmud- como los documentos religiosos fundamentales e inmutables que deben ser interpretados de manera tradicional. 
Lo cierto es que el calificativo de ortodoxo en el judaísmo es una construcción decimonónica y nunca existió antes como tal a lo largo de la historia del pueblo judío. Fue a comienzos del siglo XIX, y como respuesta a la llustración judía - más conocida como Haskalá- y a la emancipación experimentada por las comunidades judías en algunos países de Europa Occidental, que surge un movimiento reformista que llevaría a la liberalización de las prácticas religiosas y la integración de los judíos en las sociedades modernas. Fue así que el movimiento reformista acuñó el término de ortodoxos para calificar a quienes siguieron practicando la religión de la manera ancestral.

El resultado más amplio y familiar de la Haskalá fue el judaísmo reformista moderno. La confianza para ejercitar la selectividad hacia la tradición judía derivada del conocimiento histórico de su pasado, la necesidad de los judíos alemanes de clase media de practicar una religión visiblemente similar al protestantismo alemán y la filosofía kantiana impulsaron el auge de la reforma o del judaísmo liberal en la Alemania del siglo XIX. (Cantor, 1994, p. 262).

Fue en Alemania que los judíos buscaron modernizar la educación hebraica en vista de los nuevos conocimientos científicos, negando la autoría absoluta y divina de la Torá, y declarando que sólo las leyes bíblicas vinculadas a la ética eran obligatorias, al mismo tiempo que establecían que la Halajá (la ley judía) ya no debía ser vista como normativa para los judíos inmersos en las nacientes sociedades seculares de la Europa Occidental.

"En Alemania el movimiento para la reforma creció a pasos agigantados. Los judíos reformistas ya no rezaban en hebreo. Afirmaban su judeidad a través de libros de rezos revisados y su germanidad descartando el rezo tradicional sobre la venida del Mesías "en nuestros días". Ellos ya no deseaban ser guiados a la Tierra Prometida. Alemania era su hogar amado". (Elon, 2002, p. 208).

No sorprende entonces que en este cisma moderno de la milenaria tradición judía el término de ortodoxo haya sido utilizado inicialmente de un modo peyorativo. $Y$ tampoco sorprende que los judíos tradicionalistas de ese entonces lo resintieran, tal como lo evidencia el rabino Samson Raphael Hirsch en un escrito de 1854: "El judaísmo "ortodoxo" no reconoce variedades del judaísmo. Concibe al judaísmo 
como único e indivisible. No reconoce un judaísmo mosaico, profético y rabínico, ni un judaísmo ortodoxo o liberal. Sólo conoce el judaísmo y el no judaísmo". (Hirsch, 1854, p. 198).

Hoy el término ortodoxo ya no tiene la carga peyorativa que pudo haber tenido originalmente y sirve para describir a las dos grandes corrientes de la actualidad: la ortodoxia moderna o neo-ortodoxia y los jasidim, a menudo llamados ultraortodoxos.

Pese a que existen diferencias en la manera en que las dos corrientes abordan ciertos temas como por ejemplo el grado de integración de los judíos ortodoxos a las sociedades seculares, la obligación talmúdica de aprender y practicar una profesión y el rol de la mujer en la sociedad religiosa moderna, lo cierto es que ambas coinciden en su respeto por la interpretación irrestricta de la Torá y sus mitzvot (preceptos), la práctica de las reglas dietéticas judías (kashrut), el cumplimiento del shabat (día de descanso) y de la tefilah (rezo). Las corrientes ortodoxas se consideran las verdaderas herederas de la tradición judía por lo que consideran a los movimientos judíos no ortodoxos como desviaciones de la tradición, calificándolos incluso de heréticos. En cuanto a la concepción de la identidad judía, las corrientes ortodoxas reconocen como judíos sólo a quienes sean hijos de madre judía y se oponen tenazmente a los matrimonios mixtos, teniendo como fin último evitar la asimilación.

La ortodoxia moderna o neo-ortodoxia incluye un espectro bastante amplio de movimientos. En general, la neo-ortodoxia sostiene que la ley judía es normativa y vinculante, mientras que simultáneamente le otorga un valor positivo a la interacción con la sociedad contemporánea. No obstante, para preservar la integridad de la Halajá, cualquier área de inconsistencia y conflicto poderoso entre la Torá y la cultura moderna debe ser evitada. En cuanto a su relación con el Estado de Israel, la ortodoxia moderna es en general de orientación sionista. 
Por su parte, las corrientes jasídicas (del hebreo hasidim, piadosos) promueven una segregación abierta de la sociedad gentil y a diferencia de otros judíos ortodoxos se distinguen por su particular organización social centrada alrededor de los rebbes, su identificación con una historia única y por el entusiasmo y la alegría que imponen al puntillismo de la ortodoxia judía.

El jasidismo es un movimiento religioso que vio la luz en la segunda mitad del siglo XVIII en la actual Ucrania con el rabino Israel ben Eliezer, más conocido como Baal Shem Tov (1700-1760), cuya fama de piadoso y milagrero inspiró a miles de judíos de Europa Oriental en una era de constantes persecuciones y un creciente distanciamiento con las elites rabínicas. "Las formas jasídicas de piedad, humildad y entusiasmo, imbuidas de conocimientos cabalísticos, transformaron las prácticas religiosas y la autoridad religiosa. En una generación los poderes sociales y espirituales de los rebbes se convirtieron en la figura ascendente del jasidismo". (Mintz, 1998, p.169).

El movimiento jasídico - que consta de varias cortes que giran en torno a los rebbes, reconocidos por sus poderes de bendición y sanación - revitalizó las creencias y los rituales ortodoxos en Europa Central y Oriental. "El gran logro del jasidismo consistió en extraer ideas de los libros sagrados del judaísmo y trasladarlas a la vida diaria. Confirió una nueva santidad a la vida diaria y produjo un renacimiento espiritual en el judaísmo". (Hacohen, 1985, p. 47).

Pero aunque los jasidim comparten una historia, costumbres y lenguajes comunes, están divididos en una treintena de cortes distintas presentes mayoritariamente en Israel y Estados Unidos, donde se instalaron luego de que sus comunidades fueran prácticamente aniquiladas por los nazis durante la Shoah. Algunas cortes jasídicas se oponen al sionismo, llegando incluso a no reconocer al Estado de Israel. 


\section{Aumento de la ortodoxia a nivel mundial: ¿un nuevo paradigma?}

El tamaño de la población judía a comienzos del 2010 alcanzó a 13.428 .300 personas, correspondiente al 1,95 por mil de la población mundial total de 6.900 mil millones de habitantes ${ }^{1}$. Dentro de ese universo de población judía, y tal como lo indican algunos estudios demográficos, se ha constatado un crecimiento de la ortodoxia en la población tanto en Israel como en la diáspora. La estimación actual de judíos ortodoxos en Israel varía entre 900 mil a 1 millón de personas, en Norteamérica entre 550 y 650 mil y en el resto del mundo entre 120 y 150 mil personas ${ }^{2}$.

En un escenario actual en que la población judía mundial está disminuyendo, la demografía también jugaría a favor a las corrientes ortodoxas debido a que sus tasas de natalidad son casi uniformemente altas. Se estima que en Israel las familias ultra-ortodoxas tienen entre 5 y 10 hijos, mientras que las parejas que adhieren a la ortodoxia moderna tienen entre 3 a 5 hijos. Es probable que tal situación se replique en la diáspora, en un momento en que las familias judías no ortodoxas están teniendo menos hijos de los que se necesitan para reemplazar a la población. ${ }^{3}$

En opinión del sicólogo y co-director del portal Anajnu, Mijael Vera, el fenómeno del auge de la ortodoxia no se limita a explicaciones demográficas, sino que se vincula a una creciente búsqueda espiritual que surge con posterioridad al derrumbe de ideologías que guiaron los destinos de millones durante buena parte del siglo XX.

"Desde la caída del Muro de Berlín, con todas sus consecuencias de derrumbe de las utopías ideológicas, muchos judíos quisieron efectuar un retorno a sus raíces. Es el fenómeno de Teshuvá (retorno) que ha sorprendido a todo el mundo judío. Aunque parezca increíble, muchos profesionales formados en el laicismo, ateos, ex marxistas, y un largo etcétera comenzaron a retornar a las sinagogas generando un complejo fenómeno de reinvención personal. El proceso es múltiple y multidireccional para el cual las sinagogas más liberales no estaban preparadas. El mundo de las ortodoxias tampoco lo estaba, pero supo responder oportunamente al generar comunidades aparentemente más adecuadas a los requerimientos modernos" (Vera, 2006). ${ }^{4}$ 
Latinoamérica no escaparía de esta tendencia mundial, la cual podría llevar a un cambio de paradigma en una población judía que tradicionalmente ha estado más alejada de la observancia religiosa.

Aunque no existan aún cifras definitivas para demostrar esta tendencia a nivel latinoamericano, valga como ejemplo el crecimiento del número de sinagogas, escuelas e instituciones ligadas a movimientos ortodoxos en los últimos años desde el Río Grande hasta la Patagonia.

En México, cuya población judía se estima entre 40 mil y 65 mil personas, ésta está mayoritariamente afiliada a la ortodoxia, con un asombroso promedio de $90 \%$ de los niños judíos asistiendo a colegios religiosos judíos. En Brasil en tanto, con una población judía superior a las 100 mil personas, el crecimiento de las comunidades ortodoxas se ha hecho particularmente patente en Sao Paulo, principalmente entre los judíos sefarditas. Incluso la liberal Río de Janeiro es hoy sede de dos escuelas ortodoxas, un kollel (grupo de estudios de la Torá para hombres casados) y un gran complejo perteneciente al movimiento jasídico Jabad Lubavitch. Finalmente en Argentina, país que concentra la mayor población judía de Latinoamérica y la sexta más grande a nivel mundial con casi 250 mil personas, la presencia ortodoxa es indesmentible con decenas de instituciones que incluyen escuelas, sinagogas, kolellim y yeshivas (centro de estudios de la Torá dirigido a los jóvenes en el judaísmo ortodoxo). ${ }^{5}$

Parece relevante destacar el caso de Argentina, que por ser el país que tiene la mayor población judía de Latinoamérica, siempre ha sido un referente en la región. En tal sentido, es preciso señalar que el colapso económico y financiero que golpeó a Argentina en 2001 dio pie para que un número creciente de niños judíos ingresaran a escuelas ortodoxas y muchas familias judías afectadas por la pobreza y el desempleo se acercaran a instituciones de caridad vinculadas a movimientos ortodoxos. De todos ellos, sin duda, el más exitoso es Jabad Lubavitch, el cual en poco más de 30 años pasó a tener 33 beit jabad (centros comunitarios), 16 escuelas, otros tantos centros educativos no formales, varias fundaciones de asistencia social, una editorial, y unos 700 empleados que junto a innumerables voluntarios se estima que han acercado a unos 45 mil judíos argentinos a este movimiento ortodoxo. (Soifer, 2010, p. 70) 
Jabad, como se le llama usualmente, fue una de las cortes jasídicas surgidas tras la muerte de Baal Shem Tov, que se expandió por todo Rusia y tuvo su sede principal en la ciudad bielorrusa de Lubavitch. Tras la Shoah, el movimiento se asentó en Nueva York, y fue desde su sede en Crown Heights, Brooklyn, que el séptimo rebbe de Lubavitch, Menachem Mendel Schneerson, inició y dirigió la exitosa expansión de una empresa evangelizadora judía hoy presente en casi todo el mundo.

De carácter mesiánico y bajo la consigna de que los judíos deben conocer y cumplir los preceptos de la Torá, Jabad ha acercado a decenas de miles de judíos a la observancia, frenando así su asimilación. Utilizando las herramientas del marketing y del fundraising moderno, Jabad se ha convertido en el principal movimiento ortodoxo jasídico a nivel internacional.

"El judaísmo como proveedor de una forma de vida fue el impuso inicial que llevó a muchísimos jóvenes a ingresar a Jabad. Ellos constituyeron la primera frontera de un movimiento que puede pensarse integrado por dos límites: uno interno, donde los miembros cumplen con todas las mitzvot, preceptos y leyes que determinan la forma de vida adecuada para el judío observante, y una externa, donde se ubican aquellos que empiezan a acercarse de forma lenta y pausada, seducidos, quizás, por la consistencia en la forma de vida de aquellos rabinos y miembros de la comunidad de la frontera interna". (Soifer, 2010, p. 111)

Para el académico chileno Isaac Caro el renacer de la ortodoxia entre la población judía latinoamericana, reflejada en buena parte por el éxito de grupos como Jabad, podría chocar con el modelo laico que hasta el momento prevalece como mayoritario y, eventualmente podría llevar a una pugna en los patrones identitarios de las comunidades judías de la región.

"A comienzos del siglo XXI parece consolidarse un modelo judío laico, progresista, descentralizado, que es resultado de los procesos de globalización y crisis identitarias que se viven en un período de radicalización de la modernidad. Al mismo tiempo y, como resultado de estos mismos procesos, este modelo laico podrá verse enfrentado a un crecimiento de posiciones ortodoxas judías, tanto en Israel como en la diáspora, que lleven a una polaridad y choque con patrones identitarios más exclusivos: en un polo, uno más inclusivo, de mayor apertura y diálogo, en donde el judaísmo y lo judío se definan en un sentido cada vez más plural y, en otro, uno más excluyente, que abogará porque la religión y las concepciones más ortodoxas de la misma prevalezcan en la definición del ser y del quehacer judío". (Caro, 2008, p.92). 


\section{Judíos ortodoxos en Chile}

El crecimiento de las comunidades ortodoxas es también una realidad que se hace cada vez más visible en Chile. Nuestro país se encuentra en la posición 18 en la lista de países con el mayor porcentaje de población judía, con una población que ronda los 20.500 individuos, los que representan el $0,12 \%$ del total de la población chilena y el $0,2 \%$ del total de la población judía en el mundo. ${ }^{6}$

De acuerdo al Estudio Socio-Demográfico de la comunidad judía de la Región Metropolitana, en 1995 sólo el $3 \%$ de los judíos chilenos se definían como ortodoxos, una cifra significativamente menor al porcentaje de judíos que se declararon como conservador (35\%), laico o no religioso (23\%), tradicionalista (19\%) y reformista (14\%).(Berger, 1995, p. 68). Si se comparan las cifras con Israel, donde cerca del $27 \%$ de la población se considera ortodoxa o Estados Unidos con $10 \%$, lo cierto es que la ortodoxia constituía una minoría indesmentible en relación al resto de la comunidad judía nacional.

El cambio, no obstante, se ha dado en los últimos quince años, pues ha sido en ese período en el cual el crecimiento de las comunidades ortodoxas se ha dado con fuerza en el país. Prueba de ello es el número de instituciones vinculadas a la ortodoxia que existen hoy en Santiago, el cual no tiene precedente en la historia de la comunidad judía local. Así por ejemplo, hoy existen tres sinagogas ortodoxas vinculadas a la comunidad ashkenazi en un radio geográfico muy delimitado entre Las Condes y Lo Barnechea -Aish Hatorah Chile, Kehilá Jafetz Jaid y Jabad Lubavitch- además de la Kehilá Jaredit Jazon Ish, en Providencia, mientras se espera el desembarco de la primera sinagoga ortodoxa sefardita en el país. A esto hay que sumar una institución para jóvenes -Morashá- y tres mikves (baños rituales para mujeres) ubicados junto a las sinagogas de Kehilá Jaredit Jazon Ish, Kehilá Jafetz Jaim y Jabad Lubavitch. El cuadro no podría estar completo sin mencionar la existencia del Maimónides School, el primer y único colegio ortodoxo judío del país, fundado en 1998 por el inversionista y filántropo canadiense, Albert Friedberg. 
Pero nada podría hacer más evidente la creciente presencia ortodoxa en Chile que la aparición de un barrio ortodoxo ubicado en la avenida Quinchamalí, en la zona ubicada entre Las Condes y Lo Barnechea, a pasos de las sinagogas ortodoxas del sector.

"En el cerro Quinchamalí, el barrio más exclusivo, hacia la cordillera, hay una docena de casas. Empresarios, gerentes, importadores, dueños y gerentes de grandes tiendas. Jubilados. Un par de viudas. Rabinos con sus esposas. Profesores del Instituto Hebreo y la UC. Matrimonios jóvenes con muchos hijos. Suman cerca de setenta familias y alrededor de 400 personas" (Dellapergola, 2010, p.71)

Quinchamalí es el primer y único barrio judío ortodoxo de Chile. Y de allí que en el sector hoy existan varios servicios dedicados a esta pequeña pero floreciente comunidad. Restaurantes de sushi y pizzerías kosher, almacenes con productos exclusivamente kosher, peluquerías que atienden a mujeres ortodoxas lejos del ojo de los intrusos, góndolas completas con productos kosher en los grandes supermercados del barrio alto y proyectos inmobiliarios de departamentos diseñados exclusivamente para cumplir con las necesidades de las familias ortodoxas, dan cuenta de que hoy existe un público para estos bienes y servicios, el que además tiene un alto poder adquisitivo.

La concentración de las instituciones judías -ortodoxas y no ortodoxas- y de los servicios afines en este exclusivo sector de Santiago ha dado pie a críticas por el abandono en que han quedado muchos judíos que no viven en la zona oriente de la capital. Así pues, en la Región Metropolitana, principal centro de concentración judía en Chile, las sinagogas, el colegio Hebreo y los centros comunitarios judaicos se han trasladado hacia el barrio alto.

"Los escasos locales de comida kosher se han establecido también en las comunas del sector oriente de Santiago. Y, a pesar de los esfuerzos de los líderes por mantener la solidaridad interna en sus comunidades, simbólica y socialmente se ha producido una brecha que ha terminado por provocar un autoaislamiento, silencioso, de numerosos judíos capitalinos". ${ }^{7}$ (Guzmán Sinkovich, 2002).

La prosperidad económica de la población judía sin duda está detrás de esta creciente elitización que estaría dejando fuera a algunos sectores de la judería santiaguina. El mundo ortodoxo, aunque más pequeño, no sería la excepción y ante la creciente demanda por instituciones y servicios en otras zonas 
de Santiago, ya han surgido voces indicando que podrían instalarse sinagogas ortodoxas fuera del sector oriente de la capital. $^{8}$

\section{Historia de las comunidades ortodoxas en chile}

Analizar el creciente aumento de las comunidades ortodoxas en el Chile del siglo XXI requiere dar una mirada a lo que ha sido la historia de las mismas en los últimos cien años. Cabe señalar en este punto que, dada la inexistencia de documentación bibliográfica, la reconstrucción histórica se hizo en base a entrevistas a rabinos ortodoxos.

La ortodoxia en Chile ha estado históricamente vinculada a los judíos ashkenazis que llegaron a comienzos del siglo XX, tras la Segunda Guerra Mundial. La comunidad sefardita, que llegó antes que la ashkenazi y se asentó en Temuco, pese a venir de un mundo tradicionalista, se asimiló rápidamente. El rabino Avi Horowitz, director del Maimónides School y conocedor de la historia de las comunidades ortodoxas en Chile califica como una "anomalía" la rápida asimilación y proceso de laicización que experimentó la comunidad sefardita chilena ya que "por definición los sefaradíes en el mundo son tradicionalistas"9.

Fue con la llegada de las corrientes migratorias de judíos europeos antes y después de la Segunda Guerra Mundial que surgió la primera comunidad ortodoxa en Santiago, aunque siempre con un carácter muy limitado en cuanto al número de individuos que las integraban. Según el rabino Moishe Najimovsky de la sinagoga Kehilá Jaredit Jazon Ish, “(...) los ortodoxos que llegaron a Chile eran muy pocos, no más de 10 o 15 familias, fundamentalmente húngaros" ${ }^{\prime 10}$. 
Las pocas familias judías ortodoxas presentes en Chile, y que se reunían en una sinagoga ubicada en la calle San Francisco, migraron en masa desde el país durante el gobierno de la Unidad Popular (19701973) debido a la turbulencia política que se vivió durante esos años. "Fue como un doble golpe (para la comunidad ortodoxa): los judíos rusos que tenían temor del comunismo salieron el '70 y los judíos izquierdistas religiosos salieron del país tras el golpe", sostiene el rabino Horowitz, quien agrega que para 1973 "ya casi no había ninguna vida ortodoxa organizada en Chile".

El panorama experimentaría un pequeño cambio en 1976 cuando algunas familias ortodoxas regresaron a Chile y se fundó una sinagoga en la calle Miguel Claro en Providencia. "A esa comunidad llegó mi papá directamente de Israel como rabino para mantener la comunidad ortodoxa en Chile", relata el rabino Najimovsky, quien nació en Chile y emigró junto a su padre de regreso a Israel en 1980.

Pero el verdadero intento por refundar y fortalecer una comunidad ortodoxa en Chile vendría de la mano de Albert Friedberg a comienzos de la década del '80. Este inversionista y filántropo judío canadiense que pasó su infancia en Uruguay, llegó a Chile a fines de los '70 atraído por el proceso de liberalización económica que estaba llevando adelante la Junta Militar asesorada por los Chicago Boys. Friedberg tuvo gran éxito en sus negocios en Chile -incursionando en el mundo financiero, la industria agrícola y hasta en medios de comunicación- y decidió por iniciativa propia promover el surgimiento de una comunidad ortodoxa en Santiago.

Según el rabino Horowitz (quien es yerno de Friedberg) para ese entonces “(...) la única forma que él tenía de hacer algo en Chile era mandar shlijim (emisarios)", por lo que recurrió a Jabad Lubavitch. Le contactaron con el rabino israelí Menashe Pernam, quien hasta el día de hoy es el rabino de Jabad en Santiago, y en sociedad con el empresario brasileño Edmond Safra financiaron el nuevo emprendimiento ortodoxo en Chile en 1981. La asociación, no obstante, no prosperó y al cabo de unos años Friedberg se distanció de Jabad y el rabino Pernam siguió por su cuenta. Hoy Jabad tiene su sede en La Dehesa - 
anteriormente estuvo en el barrio El Golf- en una imponente casona financiada gracias a la donación del sobreviviente del holocausto David Feuerstein ${ }^{11}$.

Tras el quiebre con Jabad, Albert Friedberg se abocó a la creación de un kollel, el que instaló en la calle Ezequías Alliende en Providencia para lo cual trajo parejas ortodoxas desde Argentina e Israel, así como de una sinagoga en la calle Lota en la misma comuna. Este esfuerzo, indica el rabino Horowitz, duró hasta 1994 y "el kollel tuvo épocas más y menos exitosas, pero siempre con un impacto limitado". Entretanto, la sinagoga de la calle Miguel Claro quedó a la cabeza del rabino israelí Itzhak Shaked, quien más tarde saldría de esa comunidad y fundaría su propia sinagoga -Jafetz Jaim- en la calle Las Hortensias en Providencia, con miembros de la escindida comunidad de Miguel Claro. Jafetz Jaim más tarde se trasladaría a la calle Quinchamalí en Las Condes, donde continúa hasta el día de hoy.

Pero pese a todos estos movimientos, la ortodoxia judía en Chile seguía siendo muy limitada. Esto habría de cambiar a mediados de los años '90, cuando Friedberg trajo a Chile a representantes de la organización Aish Hatorah, una organización sin fines de lucro de carácter neo-ortodoxo con sede en Israel que promueve la enseñanza del judaísmo de una manera moderna.

El rabino Horowitz, quien llegó a Chile desde Estados Unidos para trabajar en Aish Hatorah a mediados de la década pasada, señala que fue el trabajo con los jóvenes universitarios judíos y las becas para viajes a Israel financiadas por dicha organización lo que causó el mayor impacto y derivó en el actual auge de las comunidades ortodoxas en Chile. "Estas becas permitieron mandar unos 20 chicos anualmente, quienes se entusiasmaron mucho con el judaísmo, cada uno con su propio nivel de inspiración, y en verdad ésta fue la semilla de la futura comunidad ortodoxa en Chile".

Otro hito fundacional fue la creación en 1998 del Maimónides School, otra iniciativa de Albert Friedberg para promover la ortodoxia judía en Chile. Hasta entonces nunca había existido un colegio ortodoxo en el 
país y sólo habían ganim (preescolares) en el limitado mundo de la ortodoxia judía santiaguina. Inspirado en el modelo de los Hebrew Day Schools estadounidenses, el colegio Maimónides comenzó con apenas 15 alumnos en una casona de la calle Alcántara. Hoy tiene una matrícula de 300 alumnos de primero a cuarto medio, y cinco mil metros cuadrados construidos en Lo Barnechea, ubicándose entre los diez mejores colegios en cuanto a resultados de la PSU. Combinando educación religiosa judía ortodoxa con calidad académica, el Maimónides School hoy se ha convertido en un referente educacional, que de paso ha restado alumnos y lustre al Instituto Hebreo, el tradicional colegio judío de Santiago.

La ortodoxia judía chilena está representada mayoritariamente por la corriente neo-ortodoxa, la cual con un lenguaje fresco y juvenil ha captado la atención de la juventud judía local. Los movimientos jasídicos sólo están representados por Jabad (con sedes en Santiago y Pucón), movimiento que sin embargo no ha tenido el crecimiento explosivo que sí ha experimentado en países vecinos como Argentina.

Entre los rabinos de las cuatro sinagogas ortodoxas de Santiago no existe una instancia de coordinación formal, y sólo ocasionalmente trabajan en conjunto en pos de objetivos comunes o causas benéficas. Por el contrario, existe más bien una competencia abierta en la carrera por acercar a los judíos seculares de vuelta a la religión. Los feligreses tampoco asisten indistintamente a una u otra de las sinagogas ortodoxas. Y es que tal como dice el rabino Najimovsky a los judíos ortodoxos chilenos “(...) les gusta su propio rabino y su silla y celebra sus fiestas en su sinagoga. El que reza acá no reza allá".

\section{Conclusiones}

\section{Razones del auge ortodoxo y su impacto en la judería chilena}

Tras pasar revista a los cambios experimentados en la comunidad judía ortodoxa chilena y los principales hitos de su historia reciente, cabe preguntarse a modo de conclusión cuáles son las razones que explicarían el creciente interés que hoy genera la ortodoxia entre la comunidad judía local, particularmente entre los más jóvenes. 
Existen varias razones que se esgrimen para explicar este fenómeno. Estas van desde la apetencia de espiritualidad en una sociedad cada vez más globalizada pero al mismo tiempo cada vez más alienante, hasta un proselitismo muy bien diseñado que ha apuntado a la comunidad judía chilena y ha sido acompañado de ingentes recursos financieros.

Los entrevistados enfatizan el trabajo de difusión religiosa que se ha hecho en la última década, y que se ha enfocado fundamentalmente en los más jóvenes. Pero dejan entrever asimismo que la neo-ortodoxia se ha beneficiado de una suerte de declive de las instituciones tradicionales de la judería chilena -como las sinagogas conservadoras y reformistas, los campamentos juveniles y otras instancias que históricamente han reunido a la comunidad-, las cuales progresivamente han ido perdiendo adeptos. Según Mijael Vera, la declinación de dichas instituciones se explica:

“(...) porque los "retornados" comprendieron que lo distintivo de lo judío en la modernidad es muy amplio, es realmente una oferta variada: son imperativos religiosos, son valores éticos, son normas sociales, son tradiciones ancestrales, son creencias populares, son pensamiento y filosofía judía, son costumbres locales y también costumbres globales y compartidas, son instituciones comunitarias y son legados culturales amplios. Es conciencia, son contenidos. Y esos contenidos no los estaban vivenciando en el mundo secular" (Vera, 2010).

El rabino Najimovsky va más allá y señala que en las Altas Fiestas judías de este año se hizo evidente que la altísima asistencia de público a las sinagogas ortodoxas (no sólo por parte de quienes adhieren formalmente a la ortodoxia, sino principalmente de quienes sienten algún grado de identificación con ésta) demostró que ésta está dando la pelea numérica a las tradicionales grandes sinagogas conservadoras de Santiago. "Si sumas la cantidad de gente que vino a esta sinagoga, a Jabad, a Quinchamalí, a Aish Hatorah y lo comparas con la gente que fue a las sinagogas grandes de arriba, verás que ya no es tanta la diferencia", dice Najimovsky. Y resume su análisis en una sola frase: "El judío liberal chileno ha estado asustado en los últimos años". 


\section{Notas}

${ }^{1}$ DellaPergola, Sergio. World Jewish Population 2010. The Hebrew University of Jerusalem.

${ }^{2}$ World Jewish Population. The estate of Orthodoxy http://www.simpletoremember.com/vitals/worldjewish-population.htm

${ }^{3}$ Elazar, Daniel J. How strong is Orthodox Judaism Really? The demographics of Jewish Religious Identification. Jerusalem Center for Public Affairs, http://www.jcpa.org/dje/articles2/demographics.htm ${ }^{4}$ Entrevista a Mijael Vera, sicólogo y co-director del portal Anajnu. Noviembre, 2011.

${ }^{5}$ World Jewish Population. The estate of Orthodoxy http://www.simpletoremember.com/vitals/worldjewish-population.htm

${ }^{6}$ DellaPergola, Sergio. World Jewish Population 2010. The Hebrew University of Jerusalem. http://www.jewishdatabank.org/Reports/World_Jewish_Population_2010.pdf

${ }^{7}$ Guzmán Sinkovich, Patricio. Identidad Judía en Chile. Revista Le Monde Diplomatique, Octubre 2002.

${ }^{8}$ Vera, Mijael. Entrevista al rabino Matías Libedinsky: Vamos a construir sinagogas en otras partes de Santiago. Portal Anajnu Chile. http://www.anajnu.cl/entrevistaRabLibedinsky.htm

${ }^{9}$ Entrevista al rabino Avi Horowitz. Santiago, Octubre 2011

${ }^{10}$ Entrevista al rabino Moishe Najimovsky. Santiago, Octubre 2011

${ }^{11}$ Mohor, Daniela. Judías ortodoxas en Chile: Bajo la ley de la Torá. Revista YA de El Mercurio, Octubre 2010. 


\section{Bibliografía}

BERGER, Gabriel. Estudio Socio-demográfico de la Comunidad Judía de la Región Metropolitana de Santiago. Comité Representativo de Entidades Judías de Chile, Santiago, 1995.

CANTOR, Norman. The sacred chain. A history of the Jews. Nueva York, Harper Perennial, 1994, 512p.

CARO, Isaac. “Identidades Judías Contemporáneas”, EN: Revista Atenea, Concepción, 2008.

DELLAPERGOLA, Sergio. World Jewish Population 2010. North American Jewish Data Bank, Storrs, 2010, 71p.

ELAZAR, Daniel J. "How strong is Orthodox Judaism Really? The demographics of Jewish Religious Identification", EN: Jerusalem Center for Public Affairs, 1991.

ELON, Amos. The pity of it all. A portrait of the German Jewish Epoch 1743-1933. Nueva York, Picador, 2002, 464 p.

FARÍAS, Roberto. “El barrio prometido”, EN: Revista Paula. Santiago, 2010.

GUZMÁN SINKOVICH, Patricio. "Identidad Judía en Chile”, EN: Revista Le Monde Diplomatique, Santiago, 2002.

HACOHEN, Shmuel Avidor. "Qué es el Jasidismo", EN: Revista Maj'Shavot, Buenos Aires, 1985.

HIRSCH, Samson Raphael. Religion allied to progress. JMW. Pág. 198.

HIRSCH, Samson Raphael. The collected writings of Rav S.R. Hirsch. Feldheim, 1997.

MINTZ, Jerome. Hasidic People: A place in the new world. Nueva York, Harvard University Press, 1998, $446 \mathrm{p}$.

MOHOR, Daniela. "Judías ortodoxas en Chile: Bajo la ley de la Torá", EN: Revista YA de El Mercurio, Octubre 2010.

SOIFER, Alejandro. Los Lubavitch en la Argentina. Buenos Aires, Editorial Sudamericana, 2010, 333p.

VERA, Mijael. Entrevista al rabino Matías Libedinsky: "Vamos a construir sinagogas en otras partes de Santiago", EN: Portal Anajnu Chile, 2010.

"World jewish population. The estate of orthodoxy", EN: Simpletoremember.com Judaism Online. 